\title{
Käsinkirjoitettujen sanomalehtien pitkä historia
}

Droste, Heiko ja Kirsti Salmi-Niklander (toim.). 2019. Handwritten Newspapers: An Alternative Medium during the Early Modern and Modern Periods. Studia Fennica Historica 26. Helsinki: Suomalaisen Kirjallisuuden Seura. 223 sivua.

\section{Anne Heimo}

$\mathrm{K}$ äsinkirjoitettuja sanomalehtiä on julkaistu satojen vuosien ajan ympäri Eurooppaa ja eurooppalaisten hallitsemissa siirtomaissa. Ensimmäiset käsinkirjoitetut lehdet julkaistiin jo 1500-luvulla, mutta suosituimmillaan lehdet olivat 1800-luvulla ja 1900-luvun alkuvuosikymmenillä. Tällöin pelkästään suomenkielisiä käsinkirjoitettuja lehtiä julkaistiin satoja, kuten folkloristi Kirsti Salmi-Niklander on monissa tutkimuksissaan tuonut esiin. Siihen nähden, miten pitkäaikaisesta ja laajasta ilmiöstä on kyse, käsinkirjoitetut lehdet ovat monelle yhä tuntematon yhteisöllisen julkaisemisen muoto ja suullis-kirjallinen genre.

Aiheesta on jonkin verran aiempaa tutkimusta, mutta se on hajaantunut eri tieteenaloille. Salmi-Niklanderin ja historioitsija Heiko Drosten toimittama Handwritten Newspapers: An Alternative Medium during the Early
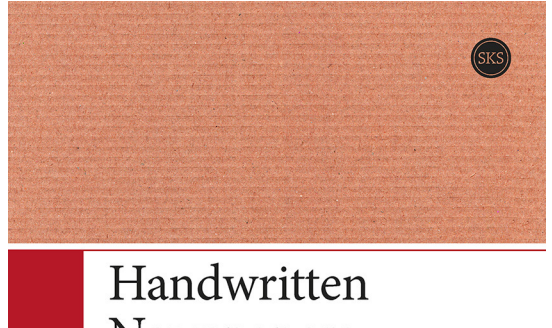
Newspapers An Alternative Medium during the Early Modern Edited by Heiko Droste and Kirsti Salmi-Niklander

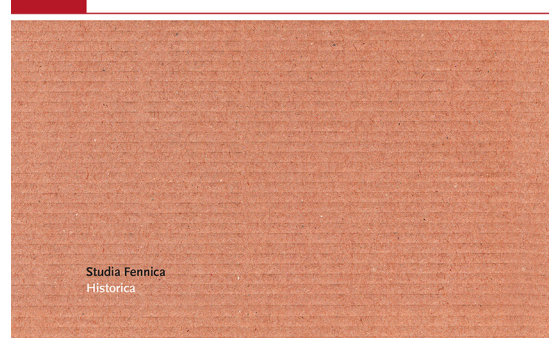
Modern and Modern Periods kartoittaa tätä moniulotteista ja laajalle levittäytynyttä ilmiötä koskevaa tutkimusta. Monitieteinen artikkelikokoelma perustuu huomioihin ja kysymyksiin, joita nousi esiin teoksen toimittajien vuonna 2015 Uppsalassa järjestämässä työpajassa. Paikalle oli varta vasten kutsuttu käsinkirjoitettujen sanomalehtien tutkijoita eri aloilta. Yleisesti aiheen tutkimus on eriytynyttä, sillä tutkijoiden näkökulmat ja kiinnostuksen kohteet vaihtelevat eikä toisten työtä siksi aina tunneta. Tämä eriytyneisyys on myös syy sille, että aiempaa kattavaa esitystä käsinkirjoitettujen lehtien historiasta tai tutkimusta sen jatkumoista ja katkoksista ei ole. 


\section{Käsinkirjoitetun sanomalehden häilyvä määritelmä}

Siitä huolimatta, että painetut lehdet ja verkkolehdet ovat vähitellen korvanneet käsinkirjoitetut lehdet, ei julkaisumuoto ole ainakaan tyystin kadonnut. Käsinkirjoitettuja lehtiä on kuitenkin vaikea määritellä. Ovatko esimerkiksi pieninä painoksina julkaistut ja monistamalla tuotetut vaihtoehtoiset poliittiset pamfletit tai DIY-kulttuuriin kuuluvat zinet käsinkirjoitettuja lehtiä? Mikä erottaa käsinkirjoitetun lehden muista vastaavista tuotteista, kuten tiedotteista, henkilökohtaisista kirjeistä tai lokikirjoista, ja miten pitkälle käsinkirjoitetun lehden määritelmä venyy?

Kokoelmassa käsinkirjoitettuja lehtiä lähestytään ensisijaisesti sosiaalisina käytäntöinä ja lehtien roolia kirjallisissa kulttuureissa pohditaan eri näkökulmista. Artikkeleissa tarkastellaan eri aikoina ja eri yhteyksissä julkaistujen lehtien piirteitä ja julkaisukäytäntöjä. Mikä on muuttunut ajan saatossa, mikä taas ei? Kokoelman kirjoittajat ovat folkloristeja, historioitsijoita sekä kirjallisuuden ja teatterin tutkijoita. Joukossa on myös yksi typografian ja visuaalisen kommunikaation tutkija. Euroopan maiden lisäksi artikkeleiden tapaustutkimukset ovat Yhdysvalloista ja Karibialta. Yksi artikkeli käsittelee Britannian kuninkaalliseen laivastoon kuuluneen aluksen HMS Chesapeaken nuorten upseerien matkalla Englannista Intiaan julkaisemaa, käsinkirjoitettua lehteä.

Uuden ajan käsinkirjoitettuja lehtiä ovat käyttäneet pääasiassa poliittisesta historiasta ja diplomatian historiasta kiinnostuneet tutkijat, jotka ovat olleet ensisijaisesti kiinnostuneita lehtien sisältämistä tiedoista, eivät itse lehdistä. Sen sijaan uusimman ajan käsinkirjoitettuja lehtiä tutkineita kirjallisuuden tutkijoita, sosiolingvistejä, etnologeja, kulttuuriantropologeja ja folkloristeja ovat kiehtoneet erityisesti ilmiön sosiaaliset ja kirjalliset ulottuvuudet. Suomalaisessa tutkimuksessa käsinkirjoitettuja lehtiä on lähestytty suullis-kirjallisena genrenä ja niitä on tutkittu lähinnä kansan kirjallistumisen ja kirjahistorian kautta sekä reading and writing from below -näkökulmasta (mm. Kuismin ja Driscoll 2013; Laitinen ja Mikkola 2013; Edlund ym. 2016; Anttonen ym. 2019).

\section{Jatkumoita ja katkoksia}

Olen seurannut pitkään tutkimusta käsinkirjoitetuista lehdistä ja olettanut tuntevani tutkimuskenttää. Kuitenkin vasta kirjaa lukiessani ymmärsin perehtyneeni lähinnä viimeisten kahden sadan vuoden aikana julkaistuihin aineistoihin ja niitä koskevaan tutkimukseen. Etenkin Heiko Drosten ja Michal Salamonikin artikkelit 1500- ja 1600-luvulla julkaistuista lehdistä avasivat minulle aivan uuden näkökulman aiheeseen ja saivat ymmärtämään, miten erilaisia lehdet ovat olleet eri aikakausina.

Artikkeleissaan Droste ja Salamonik käsittelevät kumpikin uudella ajalla julkaistuja käsinkirjoitettuja lehtiä, jotka muistuttivat pikemmin kirjeitä. Kirjeenmuotoiset lehdet kilpailivat painettujen sanomalehtien kanssa tarjoamalla sellaista tietoa valtaapitävistä ja ajankohtaisista tapahtumista, joita virallisissa lehdissä ei haluttu julkaista. Käsinkirjoitetuista lehdistä tuotettiin lukuisia kopioita, joita levitettiin kädestä käteen sekä postitse. Käsinkirjoitetut lehdet ilmestyivät painettuja nopeammin, olivat painettuja kalliimpia ja niitä voitiin myös räätälöidä tilaajan toiveiden mukaan. Käsinkirjoitettuja sanomalehtiä ostivat eliitin jäsenet, joilla oli sekä varaa maksaa palvelusta että halu pysyä perillä tuoreimmista poliittisista käänteistä, 
tapahtumista ja juoruista. Tieto oli valtaa ja keino osoittaa kuulumista eliittiin sekä toisaalta vahvistaa ryhmään kuuluvien keskinäisiä siteitä.

1800-luvulle tultaessa käsinkirjoitettujen lehtien muoto ja funktio muuttuivat. Uudella ajalla käsinkirjoitetut lehdet olivat uutisten välitystä varten eikä niiden säilyttämistä pidetty tarpeellisena, kun taas uusimmalla ajalla lehtien julkaisijat olivat monesti tietoisia niiden dokumentaarisesta luonteesta ja pyrkivät säilyttämään niitä. Joissain tapauksissa lehtiä on toisaalta tahallisesti hävitetty, jotta ne eivät olisi joutuneet vääriin käsiin ja aiheuttaneet hankaluuksia niitä julkaisseille tahoille. Uusimman ajan lehtiä on kuitenkin säilynyt enemmän kuin uuden ajan julkaisuja.

\section{Lehtien yhteisöllinen merkitys}

Uusimmalla ajalla käsinkirjoitetut lehdet alkoivat muistuttaa yhä enemmän painettuja sanomalehtiä, ja ne palvelivat ensisijaisesti lehtiä julkaisevien yhteisöjen omia tarpeita. Lehtiä julkaistiin parantoloissa, vankiloissa, kasarmeissa, kansanopistoissa ja muissa suljetuissa tai muuten tiiviissä yhteisöissä. Lehtiä julkaisivat myös yhdistykset, seurat ja osakunnat. Siirtolaisille käsinkirjoitetut lehdet olivat usein ainoa media, jossa käsiteltiin heille tärkeitä aihepiirejä yhteisön jäsenten äidinkielellä. Toisin kuin aiemmin, tämän ajan lehtiä julkaistiin yleensä vain yksi kappale. Julkistaminen tapahtui tyypillisesti lukemalla lehti ääneen jossakin yhteisön tilaisuudessa.

On suorastaan hämmästyttävää, miten yhteneväiset käsinkirjoitettujen sanomalehtien julkaisukäytännöt olivat eri maissa, kuten esimerkiksi Christian Berrenbergin ja Kirsti Salmi-Niklanderin norjalaiset ja suomalaiset tapaustutkimukset osoittavat. Lehdillä oli nimi, ja osassa käytettiin myös kolumneja ja vaihtelevia fontteja painettujen sanomalehtien tapaan. Lehdissä julkaistiin muun muassa uutisia, tiedotuksia, aatteellisia kirjoituksia, proosakertomuksia ja runoja. Monesti lehdissä pilkattiin ja parodioitiin valtamediaa. Yksi tärkeä tehtävä oli julkaista sellaista materiaalia, jota ei sen ajan valtalehdissä ollut mahdollista julkaista.

Käsinkirjoitetut lehdet olivat yhteisöllisiä julkaisuja. Joissain lehdissä juttuja kirjoittivat vakituiset toimittajat, kun taas toisissa toivottiin yhteisön jäsenten kirjoittavan lehteen riippumatta heidän kirjoituksiensa tasosta. Monet yhteiskunnalliset vaikuttajat ja ammattikirjoittajat aloittivat uransa käsinkirjoitettujen lehtien toimittajina. Esimerkiksi työväenluokkaisille naisille lehdet olivat usein ainoa mahdollisuus omien näkemysten julkaisemiseen, kuten Risto Turusen tamperelaisen Finlayson \& Compagnie -puuvillatehtaan käsinkirjoitetun lehden Tehtaalaisen analyysi osoittaa.

Painokoneiden yleistyminen 1900-luvulla ei vaikuttanut välittömästi käsinkirjoitettujen lehtien suosioon, vaan joissain tapauksissa niiden julkaisemista jatkettiin silti. 1900-luvun kuluessa käsinkirjoitetuista lehdistä tuli eräänlaisia hybridejä, joita saatettiin tuottaa myös kirjoituskoneella tai joita voitiin monistaa. Folkloristi Emese llyefalvi pohtii artikkelissaan syitä siihen, miksi jotkut eivät siirtyneet käyttämään painokoneita, vaikka tähän olisi ollut mahdollisuus. Esimerkiksi transylvanialainen pastori Dezcő Bonczidai monisti vielä 1930-luvulla hektografilla käsin kirjoittamiaan paimenkirjeitä seurakuntalaisille, koska koki tämän olevan ainoa tapa tavoittaa heidät, jotka eivät taloudellisista syistä pystyneet ostamaan painettuja uskonnollisia lehtiä. Käsinkirjoitetuilla lehdillä uskonnolliset toimijat pystyivät myös välittämään omia näkemyksiään, jotka eivät kaikissa tapauksissa noudattaneet valtakirkon oppeja. 


\section{Lisää tutkimusta tarvitaan}

Handwritten Newspapers: An Alternative Medium during the Early Modern and Modern Periods on ensimmäinen käsinkirjoitettuja lehtiä tässä laajuudessa käsittelevä teos ja siksi tärkeä. Teos kokoaa eri aloille hajaantunutta kansainvälistä tutkimusta käsinkirjoitetuista lehdistä ja myös selittää tutkimuksen sirpaleisuutta. Teoksen artikkelit tarjoavat monipuolisen kuvan käsinkirjoitettuja lehtiä koskevasta tutkimuksesta, sen haasteista ja tulevaisuuden suunnista, joihin lukeutuu muun muassa lehtien analysointi digitaalisia menetelmiä käyttäen.

Siitä huolimatta, että käsinkirjoitettuja lehtiä yhdistävät monet piirteet, niitä voidaan lähestyä eri näkökulmista riippuen siitä, onko määrittelijä kiinnostunut lehden muodosta, julkaisutavasta, käyttötarkoituksesta vai lehden sisältämistä tiedoista. Arkistoissa lehtiä on luokiteltu joskus julkaisuiksi, toisinaan taas käsikirjoituksiksi tai kirjeenvaihdoksi. Joissain arkistoissa sopivaa luokkaa ei ole löytynyt ja ne ovat päätyneet kaatoluokkaan "Varia". Käsinkirjoitetuissa lehdissä riittää siis vielä runsaasti tutkittavaa.

\section{Kirjallisuus}

Anttonen, Pertti, Cecilia af Forselles ja Kirsti Salmi-Niklander (toim.). 2018. Oral Tradition and Book Culture. Helsinki: Suomalaisen Kirjallisuuden Seura. https://doi.org/10.21435/ $\underline{\text { sff.24 }}$

Edlund, Ann-Catrine, T. G. Ashplant ja Anna Kuismin (toim.). 2016. Reading and Writing from Below. Exploring the Margins of Modernity. Umeå: Umeå University and Royal Skyttean Society.

Kuismin, Anna ja M. J. Driscoll (toim.). 2013. White field, black seeds: Nordic literacy practices in the long nineteenth century. Helsinki: Suomalaisen Kirjallisuuden Seura. https://doi. org/10.21435/sflit.7

Laitinen, Lea ja Kati Mikkola (toim.). 2013. Kynällä kyntäjät. Kansan kirjallistuminen 1800luvun Suomessa. Helsinki: Suomalaisen Kirjallisuuden Seura.

Dosentti Anne Heimo toimii folkloristiikan ma. professorina Turun yliopistossa. Hän on tutkinut Australiaan muuttaneiden suomalaissiirtolaisten Erakko-yhdistyksen vuosina 1902-1904 julkaisemaa käsinkirjoitettua sanomalehteä Orpoa. 